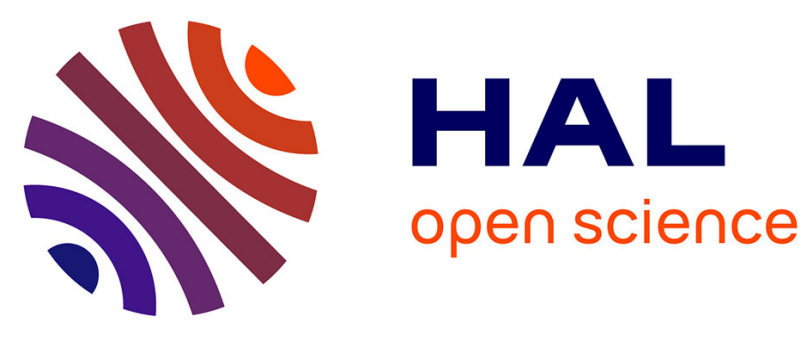

\title{
Conclusion and Discussion
}

Carine Milcent

\section{To cite this version:}

Carine Milcent. Conclusion and Discussion: A prospective view of the healthcare Chinese system. Healthcare Reform in China From Violence To Digital Healthcare, Springer International Publishing, pp.225-241, 2018, 978-3-319-69735-2. 10.1007/978-3-319-69736-9_10 . hal-03517143

\section{HAL Id: hal-03517143 \\ https://hal-pjse.archives-ouvertes.fr/hal-03517143}

Submitted on 7 Jan 2022

HAL is a multi-disciplinary open access archive for the deposit and dissemination of scientific research documents, whether they are published or not. The documents may come from teaching and research institutions in France or abroad, or from public or private research centers.
L'archive ouverte pluridisciplinaire HAL, est destinée au dépôt et à la diffusion de documents scientifiques de niveau recherche, publiés ou non, émanant des établissements d'enseignement et de recherche français ou étrangers, des laboratoires publics ou privés. 


\title{
Conclusion and discussion
}

\section{A prospective view of the Chinese}

\section{healthcare system}

\author{
Prof. Carine MILCENT \\ Carine.milcent@psemail.eu \\ CNRS - PSE
}

Today, China's public hospitals manage 90\% of consultations for what English-speakers would call ambulatory care or outpatient care', and $90 \%$ of hospital inpatient admissions. As such, public hospitals deal with the demand for treatment by consultation just as they must deal with treatment for inpatients.

China is in the midst of a paradox. There has been a spectacular upward surge in health indicators, matching a similar increase in economic indicators. It is also a colossal market, with healthcare expenditures reaching $\$ 511.3$ billion in 2013 . ${ }^{2}$ That is equivalent to $5.6 \%$ of GDP. ${ }^{3} \mathrm{On}$ the other hand, the health system has officially been described as inefficient, and there is a toxic atmosphere between medical staff and patients.

In July 2015, an article in China Daily reported a 600,000-strong online petition by doctors calling for an end to attacks on medical staff. 'This petition came in the wake of one patient's violent attack on a doctor during his shift at a Tier-3 hospital (Longmen xian renmin yiyuan 龙门县人民 医院) in Guangdong Province. The local health and family planning commission responded by demanding that a police branch be set up inside the hospital, and regular patrols carried out, in

\footnotetext{
${ }^{1}$ Jeffrey Moe, Shu Chen, and Andrea Taylor, "Initial Findings in a Landscaping Study of Healthcare Delivery Innovation in China," IPIHD (International Partnership for Innovative Healthcare Delivery) research Report 14-01, 2014; Xuezheng Qin, Lixing Li, and Chee-Ruey Hsieh, "Too Few Doctors or Too Low Wages? Labor Supply of Healthcare Professionals in China," China Economic Review,Vol. 24, No. 1, 2013.

2 "Industry Report, Healthcare: China," The Economist Intelligence Unit, August 2014.

3 The proportion of GDP spent on healthcare was 4\% in 1990. It is $17 \%$ In the United States.

4 “600,000 Chinese Doctors Sign Petition against Hospital Violence," China Daily, 19 July 2015, www.chinadaily.com.cn/china/2015-07/19/content_21326495.htm accessed September 2017
} 
order to facilitate swifter intervention in the event of violence. Surveillance cameras and alarms were also installed ${ }^{s}$

The healthcare system has been through several phases of development. The major series of reforms ${ }^{6}$ were announced in March 2009 by the State Council of the People's Republic of China and the Central Committee of the Chinese Communist Party. They were followed by the 12th Five-Year Plan (2012-2016), and now by the 13th Five-Year Plan (2016-2020), which sets out new directions for the future.

Along with the healthcare reforms, demographic changes and increase in wealth inequity have modified the healthcare's preference demand. Different types of insurance have been implemented according to the population location and the income's level. (Figure 1).

Figure 1: Segmentation of the population

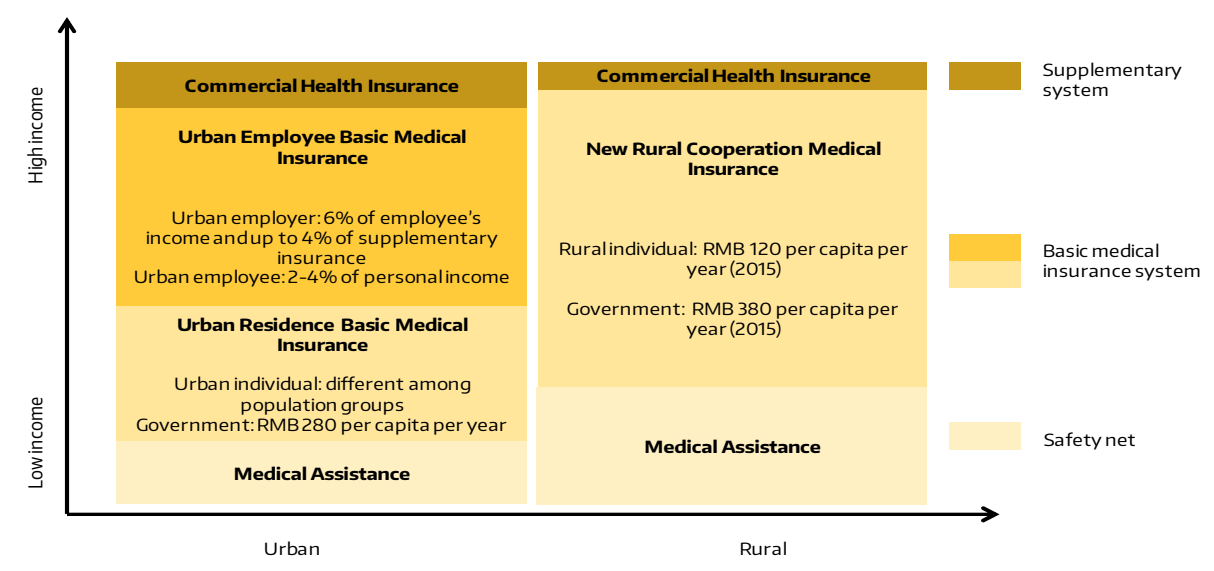

Source: Citi Research(2010); Ministry of Health (2014); UBS Research (2014)

I propose to consider a categorization of the Chinese population into three subgroups.

- A very disadvantaged population with a very low income that cannot afford to get healthcare access, even for the basic healthcare, without state intervention. This population is composed of those who benefits from the Medical Assistance but also of a part of the population eligible for the New Rural Cooperative Medical Insurance and of a part of the population eligible for the Urban Residence Basic Medical Insurance. This population is mainly from rural areas but not only with a growing part in the urban location;

- An intermediate level of population with income sufficient to afford access to basic healthcare but that cannot afford to the whole package of healthcare offered. This population has, over these three last decades, experienced an amazing change in their healthcare's quality preference. The level of quality required to satisfy their demand highly has increased. In the 80 's, considered here as the initial context, they were satisfied with a

\footnotetext{
${ }^{5}$ During my multiple visits to Tier-3 hospitals in Beijing and Shanghai, I also observed that police were routinely stationed at the entrance of every hospital complex.

${ }^{6}$ To some observers, the turning point for the reforms incorporating more aspects of social security was the 2006 speech by Party General Secretary Hu Jintao, where he introduced the notion of "harmonious society." Joe C. B. Leung and Yuebin Xi, China’s Social Welfare, Cambridge, UK, Malden, MA, Polity Press, 2015.
} 
poor level of quality for almost a free access. These days, they look for a qualified and trained physicians working in well-equipped hospitals. This population is willing to pay a substantial healthcare cost to get the level of quality they rate as they deem necessary. For this population, severe pathology or chronic disease leads to impoverishment and deterioration of the conditions of life, sometimes drastically;

- A high-income population who is able to subscribe to a private commercial insurance. This population mostly lives in urban locations. On one hand, the level of quality requested to satisfy this population is high. On the other hand, this population can afford to get access to a certain level of healthcare without calling on the public health insurance. This population is the one targeted by the commercial private insurance companies. These firms offer them a supplementary insurance in addition to the public health insurance package.

In this book, I have shown that patients' expectations have become higher over time. They have been increasingly demanding over what a "trained and qualified" doctor should mean. As a consequence, the actual, addressable supply has been shrinking, creating longer and longer queues coupled with shorter and shorter consultation times. In parallel, the price of treatment has spiraled upwards due the financial autonomy of hospitals, as the government has withdrawn its support and doctors have been incentivized to generate revenue through over-diagnosis and over-prescription.

What with skyrocketing costs, extreme waiting times, consultation time reduced to a bare minimum, added to rampant bribery throughout the system, the patient-doctor relationship has progressively become conflictive.

To address this situation, measures haven been taken to increase the number of public primary health centers and to encourage the development of the private sector in order to fuel competition among providers, or even to limit profit margins, for example by implementing "zero mark-up" policies on a list of essential medications. Yet, all of these have had limited impact. Digital technologies offer a promising route to develop innovative solutions to fix the current inefficiencies in the health system in China. Among others, apps can be used as tool to streamline demand and orient it better to avoid, or at least limit, the congestion of level 3 hospitals. We have also seen how internet can be used by the authorities, public or private insurers or hospitals themselves to improve the efficiency of the healthcare system.

On the flip side, digital solutions also have their shortcomings. One of them is that this market is entrusted to a handful of giant private players. In order to achieve certain specific goals, the Chinese government made the decision to outsource certain public service tasks to profit-driven companies. There are therefore questions being raised about the potentially dominant position in which these firms could soon find themselves.

Based on recent reforms and innovative pilot programs that are currently tested, I reckon three main streams of models are emerging and might well be cohabiting in the future.

\section{- A model run by private insurance companies,}

- Integrating digital healthcare, geographically located healthcare facilities (whatever their ownership: public, private for-profit or private non-profit) ;

- This model may merge public health insurance schemes into the package offered ; 
- A model run by internet companies,

- Primarily based on digital but integrating geographically located healthcare facilities (whatever their ownership: public, private for-profit or private nonprofit),

$\bigcirc$ with a banking service insuring the individual solvability

- A model run by public authorities at a local level,

0 with a family doctor as gatekeeper of the healthcare system access,

o with public health insurance and universal access to a basic basket of healthcare including drugs.

Thus, the main player can be the group of private insurance companies, the group of 3 Internet giant companies or the public authorities at a local level. As we will see here, the same ingredients may give different results according to the main player who drives the healthcare system.

\section{A model run by private insurance companies}

\section{The evolution}

The basic medical insurance scheme covers a large majority of the population. However, the outof-pocket health expenditures are far from being neglectful and it keeps increasing over the years.

Going back to the past for a quick reminder of the context, government and social health expenditures decreased dramatically and out-of-pocket payments increased significantly as a result of the 1990s reforms. With the 2009 reform, the share of the out-of-pocket payments decreased from 53 percent in 2005 to 38 percent in $2010 .{ }^{7}$ According to Yip et al (2012), ${ }^{8}$ the enrollment rate into the public health insurance (Urban Employee Basic Medical Insurance _UEBMI) reached nearly 93 percent in 2010 for urban residents without formal employment. The same year, 96.6 percent of rural residents had enrolled in the public medical insurance scheme there (the New Cooperative Medical System _ NCMS). ${ }^{9}$ However, the high proportion of the out-of-pocket expenditures still remains one of the major problems of the current healthcare system. ${ }^{10}$ In 2010, inpatient care expenses were reimbursed at a rate of 68.2 percent and all outpatient expenses were paid using the individual medical account. For chronic diseases that are primarily treated in an outpatient setting (as diabetes), reimbursement rates are even lower. Actually, out-of-pocket payment for outpatient treatments can exceed 90 percent of the bill.

As a consequence, although a comprehensive public medical health insurance scheme is present, there are opportunities for commercial private insurance. Holders of public insurance cannot

\footnotetext{
${ }^{7}$ Yip W., Hsiao W., Chen W, Hu S, Ma J, Maynard A. Early appraisal of China's huge and complex health-care reforms. (2012) Lancet vol 379(9818): pp833-42.

8 Yip W., Hsiao W., Chen W, Hu S, Ma J, Maynard A. Early appraisal of China's huge and complex health-care reforms. (2012) Lancet vol 379(9818): pp833-42.

${ }^{9}$ Hougaard JL1, Osterdal LP, Yu Y. The Chinese healthcare system: structure, problems and challenges. (2011) Applied Health Economics and Health Policy;9(1): pp1-13.

10 Long Q, Xu L, Bekedam H, Tang S « Changes in Health Expenditures in China in 2000s: Has the health System Reform Improved Affordability? International Journal for Equity in Health. 2013; 12: 40.
} 
tailor their insurance coverage according to their needs and their willingness-to-pay when this can be offered by a private health insurance package. For instance, single-room inpatient care can be included in the package of a private health insurance. These packages of private health insurance are a supplementary insurance for the consumers that already benefit of the public medical insurance scheme.

These packages are mainly obviously targeted at the most affluent part of the Chinese population. But, China's consumers are increasingly willing to pay for private health insurance and, in turn, looking for access to better healthcare in the form of private healthcare services in private as well as public hospitals and extended service offerings. In order to reach this goal, private health insurance companies propose today some innovative models integrating physically located healthcare as well as digital health.

The presence of public health insurances can be seen as a limit to the development of such a scheme. Actually, this assertion is only partially true. In Europe, different countries as Switzerland or France provide evidence that a supplementary insurance can be a highly developed market under the presence of a public health insurance covering the whole population.

The more the system is integrated, the biggest the chance to pay the bills. Up till now, the ability for insurance companies to tailor packages is hampered by the lack of data. Yet, there are ongoing discussions with MoHRSS in order to use some existing databases, even though there is no unified data across the Chinese territory. As of today, it is not possible to properly estimate the cost of treatment based on the pathology and the characteristics of the individuals. As the insurers have little visibility on the cost they might bear, they pass on the risk to their customers into the price of insurance policies.

To mitigate this risk, some insurance companies offer packages covering care up to a certain threshold, with or without co-payment, meaning the consumers still bear their health risk directly by themselves to a large extent.

A DRG-based payment is also an alternative to control the cost in a context of lack of health information for the insurers. The insurer reimburses the hospital for each subscriber's stay according to the fee set up ex ante and that depends on the pathology, the co-morbidity but also on the procedures performed. However, this mode of payment implies a unified healthcare database on the pathologies, co-morbidities, diagnostics, procedures as well as the details of the cost. Moreover, it implies an amount of the fee acceptable for the supplier (the hospital) and the payer (the insurance company).

Another direction is vertical integration, with health structures being part of the insurance. There are on the market an increasing number of packages based on the US managed care model. The most integrated schemes leave the complete decision of the provider to the insurance. According to the patient's pathology, he will be directed to a specific structure either belonging to the insurance company or at least approved supplier of the insurance company. This delegation of choice of provider to the insurance company is compensated by an out-of-pocket payment that necessarily has to be lower and a quality of healthcare above the standards those of the rest of the population. A good case in point is Cigna and CMC Life Insurance Company, a joint venture between Cigna and China Merchants Bank, has been building a controlled network with a large number of health suppliers since 2010 . 
To deal address the main challenges of the Chinese healthcare system, namely the quality of care and the congestion of hospitals resulting in long waiting time, insurance companies have to develop two types of services:

- Physically located healthcare facilities: they have to make connections with public hospitals in addition to set up private healthcare facilities;

- Virtual healthcare providers: we will see in the following the development of the digital healthcare in liaison with insurance companies. The online insurance market is still largely geared to property and automobile insurance, but life and health insurance are likely to follow.

\section{The revolution}

Internet is now changing the very nature of the insurance market.

Distribution network: With more than 500 million connected consumers and 300 million users of social networks, there is a huge potential for online distribution channels. So far, one identified obstacle to the development of private healthcare insurance was the amount of the broker commissions. With virtual platforms, insurers can reach directly their customers without intermediaries.

Insurance and connected mobile health devices: it has now become totally common that, in order to define the premium to pay, insurance companies ask to wear a mobile health device for a determined period of time. This device allows to measure the physical activity of the future policy, as an element of the health status condition assessment.

Legal context: In July 2015, the China Insurance Regulation Commission (CIRC) announced it would approve online insurance companies that could offer insurance services through selfoperated or third-party-operated insurance sales platforms.

As a consequence, companies are investing heavily to take advantage of this new regulation. For instance, German insurer Allianz recently joined with Baidu and Hillhouse Capital to create an online insurance company.

In addition, online services with added value can easily be bundled with the healthcare insurance package, be it from the insurer itself or from a third party. As a case in point, AliHealth has signed a memorandum of understanding with CPIC Allianz Health Insurance, subsidiary of China Pacific Life Insurance, in order to explore new online health insurance services. This service should tap into the cloud set up by AliHealth regrouping the full patient database of participating hospitals.

Innovative services also aim at bypassing long waiting times, for the moment at experimental stage. Other services include possibility to get a second opinion online regarding diagnosis and procedures to be carried out.

Obviously, billing and reimbursement will also be key to the appeal of such schemes for customers. In a very near future, Alipay, should establish operations linked to insurers that would enable patients to access their medical history and prescriptions on a digital platform and obtain real-time medical expense reimbursement. Another example is Zhongshan Hospital in Shanghai that is partnering with UnionPay to implement the "Modern Hospital" program, which includes 
Prof. Carine MILCENT

Carine.milcent@psemail.eu

CNRS - PSE

payment and reimbursement services.

As we see, the use of internet will improve both health and healthcare information. It allows to propose more targeted insurance package at a adjusted premium but, not only. This mass of information will allow to define a more accurate DRG-fee. So far, the pilot program of a DRGbased payment for hospital has delivered mixed results. One reason is the lack of relevant information for setting-up the DRG classification and associated fees. With the development of health and healthcare database as EMR (electronic medical record) and EHR (electronic health record), the availability of database for accurate information to establish a DRG classification and consistent associated fee may change the hospital's reimbursement rule in the next future. For instance, Private insurance companies will contract with hospital pre-paid package for a number of DRGs defined.

\section{For whom?}

The management of the patient trajectory by insurance companies makes it possible to address the issue of referral, avoiding to systematically mobilize resources from level 3 or $3 \mathrm{~A}$ hospitals. In addition, the recent conversion of insurance companies to e-health may give birth an array of services with added value, be it to reduce waiting lines or to enable direct billing.

Nonetheless, these services are only offered to the part of the population that can afford the insurance premium, i.e. the urban population having reached a significant level of income.

\section{A model run by internet companies}

As we have already seen in various occasions, the three main internet companies, Alibaba, Baidu and Tencent are all becoming in their own way big players of the health market.

One of the key advantage they have over insurance companies is their knowledge of patient data. Even though the use of this data is limited by law, it still makes it possible to screen patients or even the population as a whole, which insurance companies are not able to do at this point in time.

The pilot trial rolled out in 2014 by Alibaba offers a good case in point of this model run by an internet company. "Future hospital", as it is called, is an integrated model of online-offline services. First the patient needs to set-up a bank account with the banking arm of Alibaba. This makes it possible to ensure his solvability. Then, e-services are offered to this patient, while storing his medical record online for any medical staff involved to be able to access the full medical history of this patient.

Concretely, the 3 internet giants have become key links in the value chain of health, in particular for telemedicine, hospital appointment management, teleconsultation, medical record management and medicine sales.

Telemedicine: As explained in the chapter on the development of digital health, Alibaba group has implemented a pilot program proposing telemedicine to a fishing village in Hubei province. 
The remote healthcare is then provided by a physician from a very high-tech hospital (level-3 or above). The aim is to develop an offer for remote areas where healthcare facilities are not accessible and where the population cannot easily travel to get access to healthcare facilities. The advantage of this offer is

- To provide a higher standard of healthcare quality than would be physically located available in the area;

- To provide an offer at an affordable cost;

- To allow the healthcare providers to consult without actually travelling to remote places;

- To share all medical information on the patient case between all healthcare medical staff;

- To allow a remote follow-up after performing the medical acts.

Another advantage of this offer is that it is bundled with the banking and pharmacy services of the Alibaba group. The patient can get the appropriate drugs from the Alibaba pharmacy subsidiary. The drugs can be sent to the remote place through postal services. The solvability of the patient is insured by his account at Alibaba financial arm. This kind of service aimed at an audience who can afford spending money for healthcare access but who cannot afford to get access to physically located high-level healthcare facilities. I can say that it roughly encompasses middle-income class located in the rural areas.

Hospital appointment registration systems: In some provinces such as the municipalityprovince of Beijing, to get an appointment in level-3 and level-3A hospitals, patients are now obliged to get an online appointment registration. This service can be provided by some apps, including the most popular app in China, WeChat from Tencent group. I presented in the chapter on digital health, the necessity for public authorities to outsource to major Internet companies the implementation of such complicated online systems, given their skill and technological advance.

These online registration systems make it possible to avoid the long line of people queuing for a doctor's consultation. It leads to a change in the climate inside the hospital by reducing the sound nuisance for the medical staff, and it also reducing the risk of contamination by minimizing the cohabitation of population suffering from different diseases. However, it does not reduce the waiting time to get a doctor's visit.

In order to avoid fake online appointments or traffic of appointment registrations, the identity of the individual is required. As a consequence, the company managing the system gets access to a lot of information concerning the patient and his pathology. This information can be used to screen the population and set up the risk of disease by individual's characteristics.

Virtual information platform: To store medical information at individual level, virtual platforms are used. As for the hospital appointment registration systems, even if local public systems are involved, the set-up and management of such systems is often outsourced to specialized commercial companies, to maximize efficiency. For instance, the Beijing municipal government has launched health iCloud platform with partial delegation to Baidu group. As a consequence, a massive stock of historical health and healthcare information, at individual level, is managed by a commercial company. They then may use it, under the regulation law constraint, to propose tailored services to the population.

Online drug sale: To complete the offer, the model is also based on online drug sales. So far, only the non-prescription drugs can be sold online. There are split into two lists with one 
Prof. Carine MILCENT

Carine.milcent@psemail.eu

CNRS - PSE

involving a specific authorization. As presented earlier, the online sale of prescription drug is still not fully authorized.

\section{For whom?}

We have seen that this model can target quite diverse audiences. It is obviously perfectly suited for well-off urban digital natives, but can also be directed to less affluent crowds. In particular, the online aspect makes it attractive for a rural population previously quite isolated from many medical resources.

\section{A model run by public authorities at a local level}

As explained in this book, level-3 and level-3A hospitals are in the inner center of the healthcare organization in China. The limit of this system is the overcrowded situation of these facilities and the extreme tension between patients and medical staff. To solve this issue, a set of measures has been taken that is bringing about a new model of healthcare system involving:

- Online booking system

- Development of healthcare centers network in the rural locations and rural areas

- Family doctor

- Consultations and drug prescriptions: from the virtual to the physical location

The context: At this point in time, it is fair to say that public hospitals cover the vast majority of medical outpatient consultations and hospital inpatient admissions. This situation has dramatic consequences on healthcare spending. It is estimated that $30 \%$ of admissions are medically unjustified. The cost of an admission is calculated to be 37 times more than that of a consultation. Furthermore, in China the length of a hospital stay is twice as long as the average time recorded among OECD nations. ${ }^{11}$

Online booking system: People usually consider it better to queue up in a hospital that can provide quality healthcare rather than to visit a more local center, more accessible but not considered to offer the desired quality of treatment. In any case, level-3 hospitals provide an "allin-one" option that CHCs (Community Healthcare Centers) and level-1 hospitals cannot offer, due to their fragmented nature. As a consequence, the first emergency is to provide a more efficient booking system. Today, the one adopted is the online booking system. To help the less familiar ones with virtual tools, a phone services is offered as well as the possibility to be assisted by going in a physically located center. This service is an improvement on both sides: demand and offer. For patients, it allows to avoid long waiting hours standing in the hall of the healthcare center/hospitals. For hospitals, it creates a more peaceful climate for the medical staff without the overcrowded noisy patients waiting to be taken in charge.

As saw earlier, Internet grant companies preempt this system. However, the key point is who takes advantages of the information contained in the database set up from the online booking system. If the public authorities at a local level area is able to use the data. they may adapt their offer to the demand. As a result, a more efficient public model could emerge.

\footnotetext{
${ }^{11}$ World Bank, “Urban China: Toward Efficient, Inclusive, and Sustainable Urbanization,” Development Research Center of the State Council, source MoH, 2011.
} 
Development of a network of healthcare centers network in rural locations: online booking systems do not solve the fundamental issue of congestion of Level-3 and $3 \mathrm{~A}$ hospitals, they just make it more tolerable. Chinese authorities are currently attempting to modify the patient trajectory by creating a network of local healthcare centers. Their main advantages are:

- Their proximity;

- The availability of the supply without the nuisance of waiting lines

Still, they have to overcome some shortcomings:

- They do not propose the "all-in-one" option that is a strong advantage of hospitals from level-2/level-3 and above ;

- The level of qualification and training of doctors is not equivalent what is offered in hospitals from level-2/level-3 and above;

- So far, there is little incentive for the patient to modify his healthcare access pattern. Given the low level of reimbursement given by public insurance for outpatient consultations, the difference in out-of-pocket payment between the patients following the new recommended trajectory and those still keeping their previous habits is minimal.

Family doctor or General Practitioner: The incredibly long waiting come in conjunction with very short consultations with doctors, often less than 3 minutes, eventually driving stress and tension between medical personnel and patients and their family. The implementation of a family doctor system is at the heat of this new system. It is supposed to both:

- Improve the communication between patients and medical staff, as well as a better knowledge over time of the patient medical history ;

- Shift the focus of hospitals to inpatient care.

As of today, the main obstacle to the implementation of family doctors resides in training, as it did not exist as such until recently. Young students must be confident in the commitment of authorities to this drastic shift in the system before choosing this career path. As far as patients are concerned, they often have yet to overcome their preventions against what they still see as insufficiently trained physicians.

Consultations and drug prescription _ from the virtual to the physical location_: To get around this lack of trust in local physicians, who are often considered with low qualification, public hospitals also set remote consultations from seasoned professionals. This system makes it possible to reduce the waiting time while monitoring any complication that may occur and require admission. Local health centers are involved in the process, functioning in network with the hospital. This makes it possible for the patient to be rapidly taken care of while benefiting to some extent from the quality of a bigger hospital. For both sides, it saves a lot of time while the hospital controls the information within its network, preventing dissemination of information which is a source of concern today.

Another point of focus not cited so far is the expenses associated to being treated. A first series of reform to deal with this issue was the zero mark-up policy mainly targeting the drug's price sold in hospital. A DRG based payment is also a way to deal with the healthcare expenses. At each DRG is associated a fee. These fees are defined ex-ante, before any hospital's activity. Then, during the activity's period, each stay is associated to a DRG according to the pathology, comorbidities and diagnoses of the patients, and for some cases, the procedures performed during the stay. At the discharge, the hospital is reimbursed for the stay according to the DRG 
associated to this stay. This reimbursement is then disconnected from all additional procedures done to the patient. This type of payment limits the incentive of over-diagnose.

As explained before, a DRG-based payment is conditional on health and healthcare database implementation (including Electronic Medical Record (EMR) and Electronic Health Record (EHR).

\section{For whom?}

This organization of the healthcare system is suitable for any patient, even though it does not offer tailored care. In practice, it is probably totally adapted for patients with lower income, while patients who have the possibility to choose their supplier might probably turn away from it, to be able to consult directly the best skilled doctors.

\section{Commonalities between the 3 models}

As a conclusion, whatever the model described, some general key points appear. All three have in common:

- A transfer of consultations out of the hospital. First because care in hospitals is very expensive. Then because hospitals are increasingly turning into high tech centers, with low human interaction between patients and physicians. There is a growing consensus, globally and not only in China, to minimize the pure hospital time while developing centers dedicated to recovery;

- An increase in the time doctors spend with patients. A genuine relationship needs to be built through this better consultation time, be it online or else ;

- A wide use of digital to improve communication between patients and doctors, but also between physicians. Connected devices enables medical staff to have truthful information regarding the patient's health status in real time. This information at individual level with very precise time sequence generate an important mass of data making could computing compulsory.

The Chinese healthcare system is in the midst of a transition. It has to transform to address its own specific issues, but the solutions that are implemented can inspire many other countries. So far, there are very few studies on this system and on the digital revolution that is happening there. There is probably material for many researchers to work on in a context where China is leading the pack in terms of digitalization of healthcare. 
Prof. Carine MILCENT

Carine.milcent@psemail.eu

CNRS - PSE

Jeffrey Moe, Shu Chen, and Andrea Taylor, "Initial Findings in a Landscaping Study of Healthcare Delivery Innovation in China,” IPIHD (International Partnership for Innovative Healthcare Delivery) research Report 14-01, 2014; Xuezheng Qin, Lixing Li, and Chee-Ruey Hsieh, "Too Few Doctors or Too Low Wages? Labor Supply of Healthcare Professionals in China," China Economic Review,Vol. 24, No. 1, 2013.

The Economist Intelligence Unit “Industry Report, Healthcare: China,”, August 2014.

Yip W., Hsiao W., Chen W, Hu S, Ma J, Maynard A. Early appraisal of China's huge and complex health-care reforms. (2012) Lancet vol 379(9818): pp833-42.

Hougaard JL1, Osterdal LP, Yu Y. The Chinese healthcare system: structure, problems and challenges. (2011) Applied Health Economics and Health Policy;9(1): pp1-13.

Long Q, Xu L, Bekedam H, Tang S «Changes in Health Expenditures in China in 2000s: Has the health System Reform Improved Affordability? International Journal for Equity in Health. 2013; 12: 40.

World Bank, "Urban China: Toward Efficient, Inclusive, and Sustainable Urbanization," Development Research Center of the State Council, source MoH, 2011. 